\title{
Effect of microfillers on the concrete structure formation
}

\author{
Olga Borziak ${ }^{1,}$, Stanislav Vandolovskyi ${ }^{2}$, Vitalij Chajka $^{2}$, Volodymyr Perestiuk ${ }^{3}$, and \\ Oleksandr Romanenko ${ }^{1}$ \\ ${ }^{1}$ Ukrainian State University of Railway Transport, Building Materials and Structures Department, \\ Feuerbach sq. 7, 61050 Kharkiv, Ukraine \\ ${ }^{2}$ Kharkiv National University of Civil Engineering and Architecture, Building Materials and Products \\ Department, Sumska st. 40, 61002 Kharkiv, Ukraine \\ ${ }^{3}$ Tines Ukraine, B. Khmelnitskogo st. 16-22, 01030 Kiyv, Ukraine
}

\begin{abstract}
Physical and mechanical properties of concrete as a composite material are determined by structure formation processes. This paper examines the effect of dispersed mineral fillers of anthropogenic origin on concrete structure formation processes and physical and mechanical properties of fine concrete. The presence of surface charge and electrosurface potential leads to the formation of electrically heterogeneous contacts between oppositely charged surfaces which determine the strength of the material as a whole. The introduction of steel microfillers leads to the formation of strong electrically heterogeneous contacts, hardening of concrete structure and increase in its strength.
\end{abstract}

\section{Introduction}

Concrete is a multi-component composite material, whose physical and mechanical properties are determined by structure formation processes. The structure formed thereby is multilevel, from the microstructure to macrostructure of concrete which is a composite material [1]. Each level of the structure is determined by the dimensions of structureforming elements and has certain structural characteristics, in particular the grain separation factor and water-cement ratio [1-4]. The concrete strength properties are defined by electrically heterogeneous contacts, i.e. the interaction between the oppositely charged surfaces with structural elements of all specified levels. The regulation of structural elements and the creation of electrically heterogeneous contacts allow us to control the properties of concrete on the whole.

Introduction of dispersed mineral admixtures, including active admixtures and fillers which have a significant impact on the structure processes, is one of such effective ways to improve the technical properties of concrete. The substances of technogenic origin and the production waste, i.e. substances with a certain mineral composition and a certain degree of dispersion are highly recommended for use as fillers.

* Corresponding author: borziak.olga@gmail.com 
Mineral and polymer fibers [3], mineral powders such as silicate, carbonate powders or ash $[1,4]$ are most commonly used as fillers. Increase in the structure strength of a filled composite material is reached by achieving the optimum concentration of a dispersed phase; the definite particle dispersibility provides the best structural characteristics, including close packing and the maximum system consolidation [1, 4]. Empirically, it has been found that the dependence of concrete strength on the amount of admixtures of microfillers is of an extreme nature. Excessive content of high-dispersed microfillers may result in the occurrence of self-stressing sections and cracking formation [1,4].

The aim of the study is to disclose the mechanism of the structure formation of fine concrete with silicate and metallic microfillers.

\section{Development of hypothesis on structure formation processes in fine concrete with steel powder as filler}

According to [5-9], the structure and strength of composite materials such as concrete depend on the electrosurface properties of all the components.

In water-dispersed systems, which include the cement stone of concrete, the particles of an inorganic dispersion phase have a surface charge and an electrical surface potential [7]. Electrically heterogeneous contacts (EHC) are formed between oppositely charged surfaces, which define the strength of a material on the whole (Fig. 1). The strength of these contacts is ensured by ion-ion interactions between the potential-determining ions (PDI) of the surfaces, and ion-dipole interactions between the potential-determining ions and the molecules of adsorption layers of water [8]:

$$
R^{E H C}=\frac{\varepsilon \cdot z^{-} \cdot 2 e \cdot \psi_{E S}^{E}}{4 \pi \cdot \varepsilon_{1} \cdot h^{2} d_{1}}+\frac{\mu_{W} \cdot \psi_{E S}^{E}}{2 \pi \cdot \varepsilon \cdot d_{1} \cdot h_{\mu}^{3}}
$$

Where $z$ - the valence of potential-determining ions; $e$ - the electronic charge; $\varepsilon-$ the relative dielectric permittivity in the space between the potential-determining ions and the counter ions $(\varepsilon=1) ; \varepsilon_{1}$ - the dielectric permittivity of a structured water layer; $\psi_{E S}^{E}-$ the equilibrium electrosurface potential; $d_{l}$ - the distance between the potential-determining ions and counter ions when in contact; $h$ and $h_{\mu}$ - the distance between the potentialdetermining ions, or between the potential-determining ions and the water dipole; $\mu_{W}-$ the dipole moment of a water molecule.

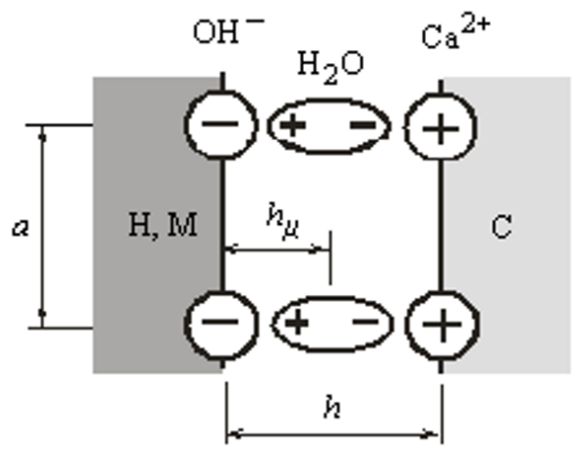

Fig. 1. Elemental electroheterogeneous contact in concrete: $\mathrm{C}$ - crystal hydratation products; $\mathrm{H}, \mathrm{M}$ - gel hydratation products or microfiller particles; $a$ - the distance between potentialdetermining ions on the surface of the substance; $h$ - the distance between potential-determining ions in EHC; $h_{\mu}$ - the distance between potential-determining ions and the dipole of water. 
Such contacts are formed between crystalline hydration products, which have a positive surface potential, and gel products of hydration, which have a negative surface potential. Ions $\mathrm{Ca}^{2+}$ are potential-determining ions of crystalline substances, while $\mathrm{OH}^{-}$are potentialdetermining ions of gel substances. The first member describes ion-ion interaction between $\mathrm{Ca}^{2+}$ and $\mathrm{OH}^{-}$, while the second describes ion-dipole interaction between $\mathrm{OH}^{-}$and the adjacent dipoles of $\mathrm{H}_{2} \mathrm{O}$.

The concrete tensile strength $R^{C}$, Pa may be defined as the product of strength of electroheterogeneous contact $R^{E H C}, \mathrm{~Pa}$, by the surface portion of such contacts in the concrete section $\gamma_{s}^{E H C}$ :

$$
R^{C}=R^{E H C} \cdot \gamma_{s}^{E H C}
$$

According to [8], $\gamma_{s}^{E H C}$ depends on the water-cement ratio $(\mathrm{W} / \mathrm{C})$ and mineral composition of the cement clinker, as well as the composition and the dispersion of fillers.

The structuring role of mineral fillers is determined by their surface properties. A variety of silicates, which are composed of more than $90 \%$ silica, are commonly used as fillers in composite materials based on mineral cementing agents. Silicate minerals have negative surface potential, which is $1.26 \mathrm{~V}$.

The metal powder consisting of steel particles used as filler has a negative electrosurface potential in the liquid phase of concrete (dispersion environment). In case of cement hydration, the particles of steel will form an EHC with portlandite $\mathrm{Ca}(\mathrm{OH})_{2}$. Portlandite has a cation $\mathrm{Ca}^{2+}$, as a potential-determining ion and an equilibrium electrosurface potential equal to $+0.53 \mathrm{~V}$. According to the image method used in calculations of silicate cementing agents [8;9], this potential-determining ion will cause an opposite charge in a steel particle equal to $-0.53 \mathrm{~V}$, and the corresponding EHC with a link of the $\mathrm{e}^{-}-\mathrm{H}_{2} \mathrm{O}-\mathrm{Ca}^{2+}[8]$ type, the strength of such contacts according to (1) is:

$$
R^{E H C}=\frac{1 \cdot 1 \cdot 2 \cdot 1.6 \cdot 10^{-19} \cdot 0.53}{4 \cdot 3.14 \cdot 2.16 \cdot 2.4 \cdot 10^{-10} \cdot\left(4.8 \cdot 10^{-10}\right)^{2}}+\frac{6.1 \cdot 10^{-30} \cdot 0.53}{2 \cdot 3.14 \cdot 1 \cdot 2.4 \cdot 10^{-10} \cdot\left(2.4 \cdot 10^{-10}\right)^{3}}=273.3 \mathrm{MPa}
$$

Thus, the introduction of the dispersed metallic (steel) microfiller into concrete will increase the quantity of strong EHC and improve the strength of concrete.

The strength of concrete is also affected by the dispersity of fillers. In accordance with [8], the introduction of large unit area fillers will increase the $\gamma_{s}^{E H C}-$ EHC concentration which, according to (2), will increase the strength of concrete as a whole. It should be taken into account [1] that the excessive amount of particles with a similar surface charge will cause the decrease in the quantity of EHC, the occurrence of repulsive forces, and the strength of concrete will consequently decrease. The maximum strength will be achieved if the ratio of these components equals 1 .

\section{Research methods and materials}

Experimental studies have been conducted to test theoretical assumptions about the impact of steel microfillers on the strength of fine concrete. Sample bars made from cement-sand mixture with microfiller - steel powder in the amount of 20,30 and $40 \%$ of the mass of cement have been produced. The steel powder of the «PGR 3» grade has been used [10], the particle size is: $>0.16 \mathrm{~mm}-5.9 \% ; 0.16 \div 0.045 \mathrm{~mm}-75.3 \% ;<0.045 \mathrm{~mm}-18.8 \%$. For comparison, control samples (sand and cement ratio is $3: 1, \mathrm{~W} / \mathrm{C}=0.4$ ) have been produced.

The hardened samples were tested for bending and compression at ages of 7,14 and 28 days. The concrete structure was explored using a scanning electron microscope. 


\section{Results of experimental studies}

The diagrams (Fig. 2, 3) show the results of the strength measurement of control (filler content $0 \%$ ) and basic samples (filler content 20,30 and 40\%) at ages of 7, 14 and 28 days.

As the results of the experimental studies show, the introduction of steel fillers significantly improves the strength of concrete in the early stages of hardening. This is particularly noticeable in the modification of the deflection strength values: the addition of $30 \%$ steel filler increases the strength of concrete at the age of 7 days by more than 4 times (8.6 MPa) compared to the control samples of concrete (1.9 MPa). Subsequently the increase in strength becomes slower and at the age of 28 days the maximum deflection strength with $30 \%$ of steel filler is $12.5 \mathrm{MPa}$, which by 2.5 times exceeds the strength of the control samples (4.9 MPa).

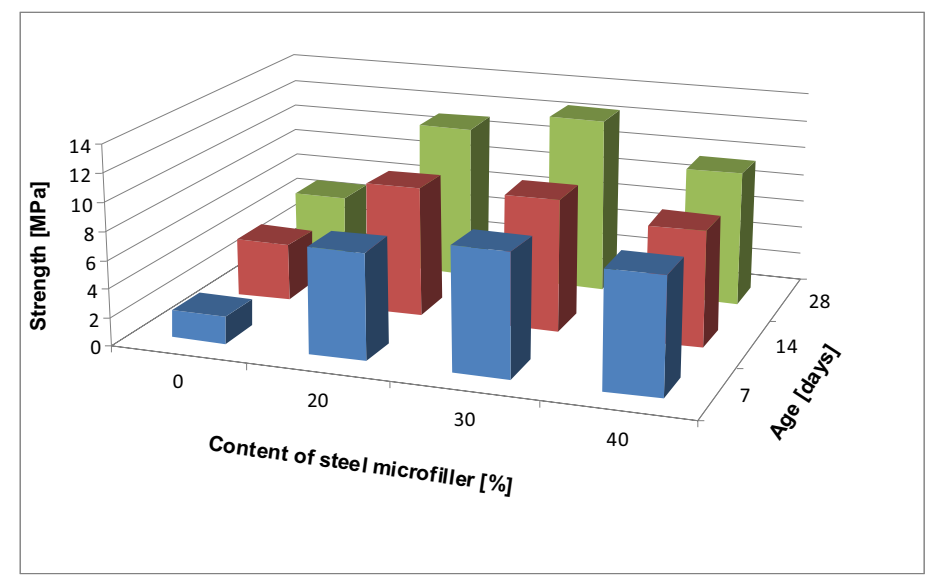

Fig. 2. Dependence of deflection strength of fine concrete on the content of steel microfiller.

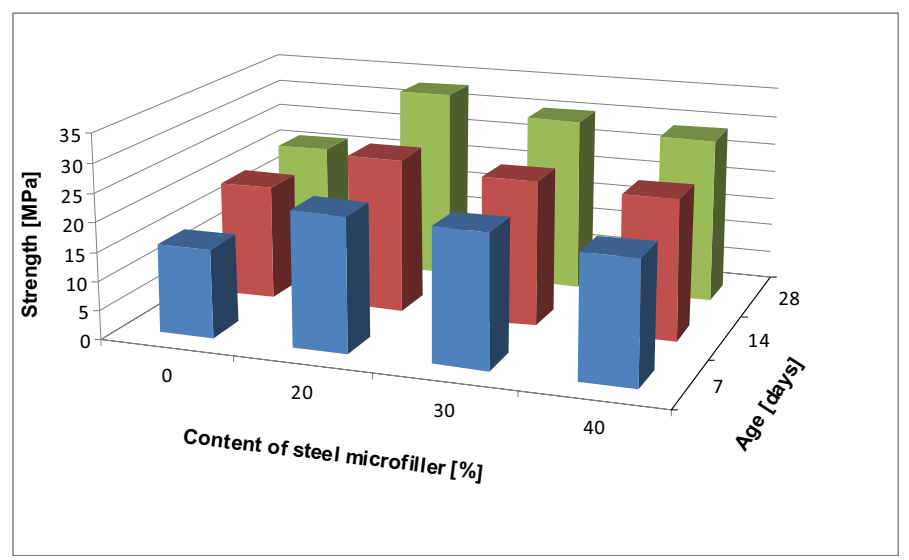

Fig. 3. Dependence of compression strength of fine concrete on the content of steel microfiller.

Fig. 4 shows the electron micrograph scanning of the shear of concrete with steel powder used as microfiller. In the center of the image there is a particle of steel microfiller having a well-defined crystal structure. The surface of the particle has been covered with prismatic crystals of hydration products. As the image shows, there is a very close contact between the steel filler particle and the cement stone. 


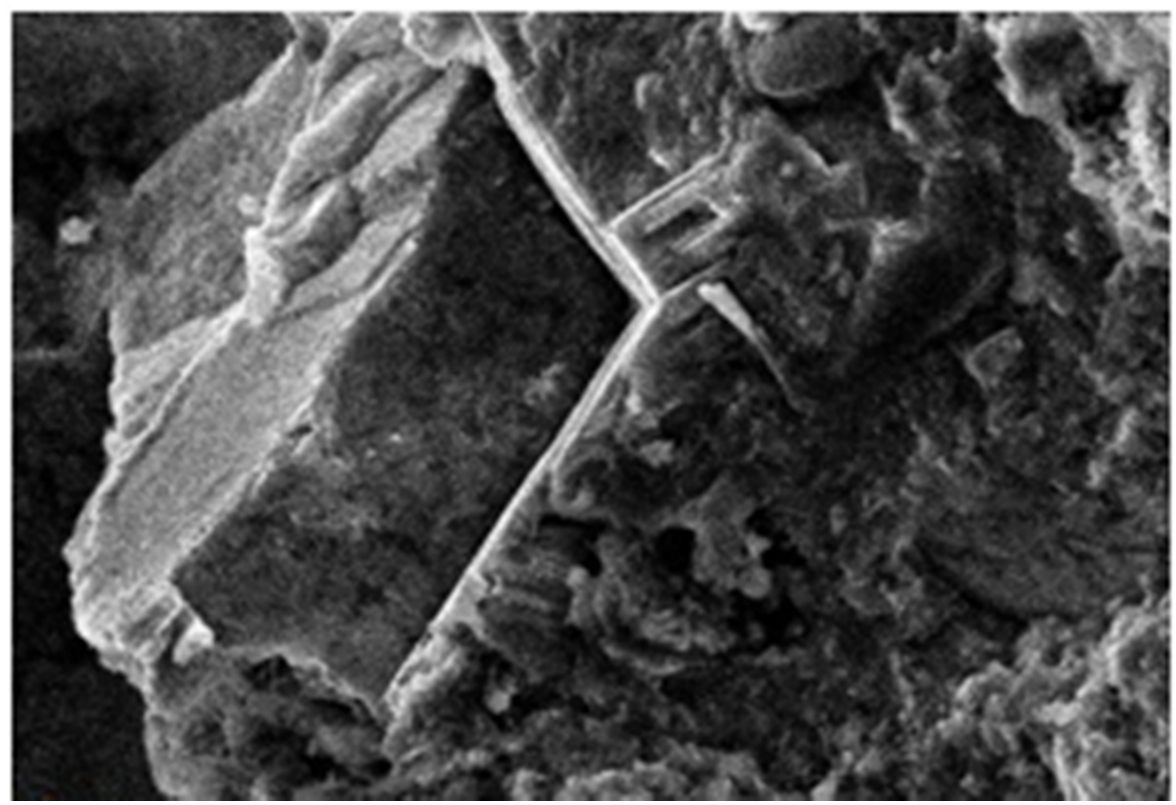

Fig. 4. The electron micrograph scanning of concrete with metal filler $(\times 1500)$.

\section{Discussion of results obtained in the study}

The results of the experimental study confirm the hypothesis developed. The introduction of steel powder as microfiller significantly increases deflective and compression strength of fine concrete. A decrease of strength due to the introduction of steel powder in the amount of more than $30 \%$ is attributed to the deviation of the number of EHC from the optimum quantity (to the deficiency of Portlandite crystalline hydrates) and the emergence of repulsive forces between like-charged (negatively charged) particles of steel powder and calcium silicate hydrate.

\section{Conclusions}

The results of the theoretical and experimental studies have found that the introduction of steel powder into a concrete mixture significantly influences the structure formation of concrete. A great quantity of strong EHC is formed between steel filler and crystallhydrate products. The optimum content of steel filler, which is $30 \%$ of the mass of cement, has been substantiated. This content of steel microfiller will increase the deflection strength by 2.5 times and the compression strength by 1.4 times.

\section{References}

1. K.K. Pushkar'ova, et al. Suchasni budivel'ni materialy $i$ konstruktyvni systemy dlya zvedennya dostupnoho zhytla ta ob"yektiv infrastruktury (VIK Print, Kyiv, 2015),

2. A.A.Plugin, A.N.Plugin, O.A.Kalinin, S.V.Miroshnichenko, D.A.Plugin, L.V.Trikoz, 18 Internationale Baustofftagung, Tagungsbericht, 1, 0874-0881 (2012)

3. A.A. Plugin, V.A. Arutyunov, T.A. Kostyuk, D.A. Bondarenko, O.V. Starkova, Sovremennyiy nauchnyiy vestnik, 32(171), 109-116 (2013) 
4. E.A. Belichenko, A.N. Plugin, A.A. Plugin, S.N. Tolmachev, EEJET, 6/5(60), 13-17 (2012)

5. A.V.Romanenko, A.A.Plugin, A.N. Plugin, O.A. Kalinin, Al.A.Plugin, EEJET, 5/10(59), 28-32 (2012)

6. A.N. Plugin, A.A. Plugin, Stroitelnyie materialyi, 7 (631), 68-71 (2007)

7. A.N. Plugin, A.A. Plugin, O.A. Plugin, A.S. Kaganovskii, O.V. Gradoboev, 18 Internationale Baustofftagung, Tagungsbericht, 1, 0656-0663 (2012)

8. A.N. Plugin, A.A. Plugin et al. Osnovy teorii tverdeniya, prochnosti, razrusheniya $i$ dolgovechnosti portlandtsementa, betona i konstruktsiy iz nikh (Naukova dumka, Kyiv, 2012)

9. V.V. Kapranov Tverdenie vyazhuschih veschestv i izdeliy na ih osnove (South Ural Publishing House, Chelyabinsk, 1976)

10. Derzhavnyy standart GOST $9849-86$ 